\title{
Analisis Dan Usulan Perbaikan Pencahayaan Pada Ruang Skripsi Perpustakaan Pusat Universitas Sebelas Maret Surakarta
}

\author{
Bambang Suhardi $^{1)}$, Pringgo Widyo Laksono ${ }^{1)}$, dan Raqibanul Hakim ${ }^{\text {(2) }}$ \\ ${ }^{1)}$ Staff Pengajar, Program Studi Teknik Industri, Universitas Sebelas Maret \\ ${ }^{2)}$ Mahasiswa Program Studi Teknik Industri, Universitas Sebelas Maret \\ Jalan Ir. Sutami 36A, Surakarta 57126, Indonesia
}

\begin{abstract}
Library with good environment will create comfort, calmness, and satisfaction for users while doing the activities. One of the aspects to consider in creating a good library environment is lighting. Lighting needs can be met from day lighting and artificial lighting. Artificial lighting had advantage in terms of relatively constant light intensity in the range of work hours, but this approach requires electric operating costs. This research analyzes the current lighting conditions in Sebelas Maret University library that influenced by day lighting and artificial lighting. The analysis process will be using software surfer V.10 based on the value of the intensity of light at each measuring point. The result indicated that the average of light intensity is still below the prescribed standard so that redesign needs to be done. In the redesign process only focuses on the artificial lighting that calculated using lumen method with two different conditions.
\end{abstract}

Keywords: artificial lighting, day lighting, library, lumen method

\section{Pendahuluan}

Keberadaan perpustakaan pada sebuah universitas menduduki peranan penting dalam mendukung kegiatan civitas akademika, khususnya dalam memenuhi kebutuhan informasi ilmiah pada universitas tersebut. Perpustakaan merupakan unit pelaksana teknis yang bersamasama dengan unit lain melaksanakan Tri darma perguruan tinggi melalui menghimpun, memilih, mengolah, merawat serta memberikan pelayanan sumber informasi kepada lembaga induk khususnya dan masyarakat akademis pada umumnya (Yuven, 2010). Melihat peranan perpustakaan yang sangat penting bagi suatu universitas, maka sudah selayaknya lingkungan dan fasilitas perpustakaan harus dirancang dengan baik. Lingkungan perpustakaan yang baik akan menciptakan kenyamanan, ketenangan dan kepuasan bagi pengguna saat melakukan aktivitas di dalam perpustakaan.

Hendra dkk, (2009) mengatakan salah satu aspek yang perlu diperhatikan dalam menciptakan lingkungan perpustakaan yang baik yaitu pada aspek pencahayaan.Aspek pencahayaan harus diperhatikan karena kegiatan di perpustakaan sebagian besar merupakan kegiatan membaca dan menulis yang sangat membutuhkan pencahayaan. Pencahayaan yang buruk dapat mengakibatkan kelelahan mata dengan berkurangnya daya efisiensi kerja, kelelahan mental, keluhan-keluhan pegal di daerah mata, dan sakit kepala sekitar mata serta kerusakan alat penglihatan (Padmanaba, 2006).

Aktivitas yang dilakukan mahasiswa di perpustakaanseperti mencari koleksi, membaca, menulis, dan bekerja dengan komputer yang semuanya itu merupakan aktivitas yang tergolong aktivitas visual yang tinggi. Aktivitas yang tergolong aktivitas dengan tingkat visual yang tinggi memerlukan pencahayaan yang baik dan cukup agar pengguna merasa nyaman dalam melakukan aktivitas. Kecenderungan dalam membatasi pencahayaan buatan di dalam suatu ruangan untuk menghemat biaya listrik, dapat meningkatkan kekhawatiran kerusakan

\footnotetext{
*Correspondance : raqib.hakim@yahoo.co.id
} 
penglihatan pada pengguna ruangan. Hal itu terjadi karena kurangnya cahaya yang dibutuhkan oleh mata dalam melakukan sebuah aktivitas visual (Ming-chin dkk,2008).

Untuk mengetahui baik atau tidaknya aspek pencahayaan pada ruang skripsiperpustakaan pusat UNS, perlu dilakukan proses observasi langsung dengan cara melihat keadaan lingkungan perpustakaan pusat UNS dan melakukan proses pengukuran nilai intensitas cahaya pada ruang baca. Berdasarkan observasi yang dilakukan, tingkat pencahayaan yang ada di ruang skripsiperpustakaan pusat UNS masih sangat kurang untuk melakukan aktivitas visual.Rata-rata intensitas cahaya pada ruang skripsi perpustakaan pusat UNS masih dibawah standar yang ditentukan SNI 03-6197-2000 yaitu sebesar 300 lux. Untuk menyelesaikan permasalahan tersebut perlu dilakukan proses perbaikan pencahayaan buatan di ruang skripsi perpustakaan pusat UNS.

\section{Metode Penelitian}

Penelitian ini terdiri dari 4 tahap yaitu pendataan kondisi ruangan, pengukuran intensitas cahaya pada tiap titik ukur, analisis tingkat pencahayaan pada kondisi existing dan usulan perbaikan pencahayaan dengan menggunakan metode lumen.Hal yang dilakukan dalam tahap pendataan kondisi ruangan meliputi pendataan fasilitas serta pengukuran dimensi ruangan dan dimensi fasilitas, serta menggambar denah armatur.Tahap selanjutnya adalah penentuan letak titik ukur pada ruangan skripsi berdasarkan SNI 16-7062-2004. Pengukuran intensitas cahaya pada tiap titik ukur dilakukan dengan menggunakan luxmeter merek luxtron lx-102. Dalam melakukan tahap analisis tingkat pencahayaan pada kondisi existing ada beberapa langkah yaitu melakukan penentuan koordinat titik ukur intensitas cahaya dan dilakukan pengolahan data dengan menggunakan software surfer V.10.

Tahap terakhir adalah proses usulan perbaikan. Pada proses usulan perbaikan metode yang digunakan adalah metode lumen. Metode lumen digunakan untuk menghitung intensitas penerangan rata-rata pada bidang kerja.Fluks cahaya diukur pada bidang kerja, yang secara umum mempunyai tinggi (tinggi khayalan) antara $80 \mathrm{~cm}$ diatas lantai.. Berikut adalah langkahlangkah yang digunakan dalam perhitungan metode lumen:

\section{a. Menentuan indeks ruangan}

Semakin tinggi dan sempit ruangan, maka semakin besar dan memerlukan iluminasi yang lebih untuk mencapai tingkat pencahayaan yang diperlukan. Untuk menghitung indeks ruangan digunakan persamaan :

$\mathrm{K}=\frac{L \times W}{h(L+W)}$.

\section{b. Menentukan koefisien penggunaan}

Sebagian dari cahaya yang dipancarkan oleh lampu diserap oleh armatur, sebagian dipancarkan ke arah atas dan sebagian lagi dipancarkan ke arah bawah.Faktor penggunaan didefinisikan sebagai perbandingan antara fluks luminous yang sampai di bidang kerja terhadap keluaran cahaya yang dipancarkan oleh semua lampu. Tidak semua cahaya dari lampu mencapai bidang kerja, karena ada yang di pantulkan oleh dinding, plafon, dan lantai.. Jika nilai Kp yang diperoleh tidak terdapat dalam tabel, maka nilainya dapat ditentukan dengan interpolasi.

$\mathrm{kp}=\mathrm{Kp} \mathrm{p}_{1}+\frac{K-K 1}{K 2-K 1}\left(\mathrm{Kp}_{2}-\mathrm{Kp}_{1}\right)$

\section{c. Menentuan kofisien depresiasi}

Besarnya koefisien depresiasi $(\mathrm{kd})$ biasanya ditentukan berdasarkan estimasi. Untuk ruangan dan armatur dengan pemeliharaan yang baik pada umumnya koefisien depresiasi diambil sebesar 0,8 sedangkan untuk penggunaan lampu baru nilai koefisen depresiasinya adalah 1 . 


\section{d. Menentukan flux luminous yang dibutuhkan}

flux luminous adalah jumlah total cahaya yang dibutuhkan oleh suatu ruangan berdasarkan tingkat pencahayaan yang dibutuhkan dan luas ruangan dibagi oleh koefisen depresiasi

$\mathrm{F}_{\text {total }}=\frac{E \times A}{k_{p} \times k_{d}}$

\section{e. Menentukaan jumlah armatur yang dibutuhkan}

penentuan jumlah armatur didasarkan dari jumlah flux luminous yang dibutuhkan dibagi besar flux luminous satu buah lampu dan jumlah lampu yang ada dalam satu armatur.

$\mathrm{N}=\frac{F \text { total }}{F_{1} \times n}$

\section{f. Menentukan daya terpasang}

penentuan daya terpasang didapat dari jumlah jumlah lampu yang ada dalam ruangan dibagi dengan luas ruangan. menurut SNI 03-6197-2000 standar minimal daya terpasang untuk ruang perpustakaan adalah $11 \mathrm{w} / \mathrm{m}$

Daya terpasang $=\frac{N \times n \times(\text { watt lampu })}{\text { Luas ruangan }}$

\section{g. Menentukan biaya listrik selama satu bulan}

penentuan biaya listrik selama satu bulan didapat dari daya terpasang di kalikan jumlah jam kerja per hari yang diasumsikan sebesar 10 jam, dikalikan 20 hari satu bulan, dan biaya beban kwh menurut PLN.

Biaya Beban=Total $\mathrm{kWh} x$ biaya beban $/ \mathrm{kWh}$

\section{Hasil dan Pembahasan}

Sebelum melakukan proses analisis dan usulan perbaikan. Hal pertama yang dilakukan adalah mengumpulkan data kondisi ruangskripsi perpustakaan pusat Universitas Sebelas Maret yang dapat dilihat pada gambar 1 .

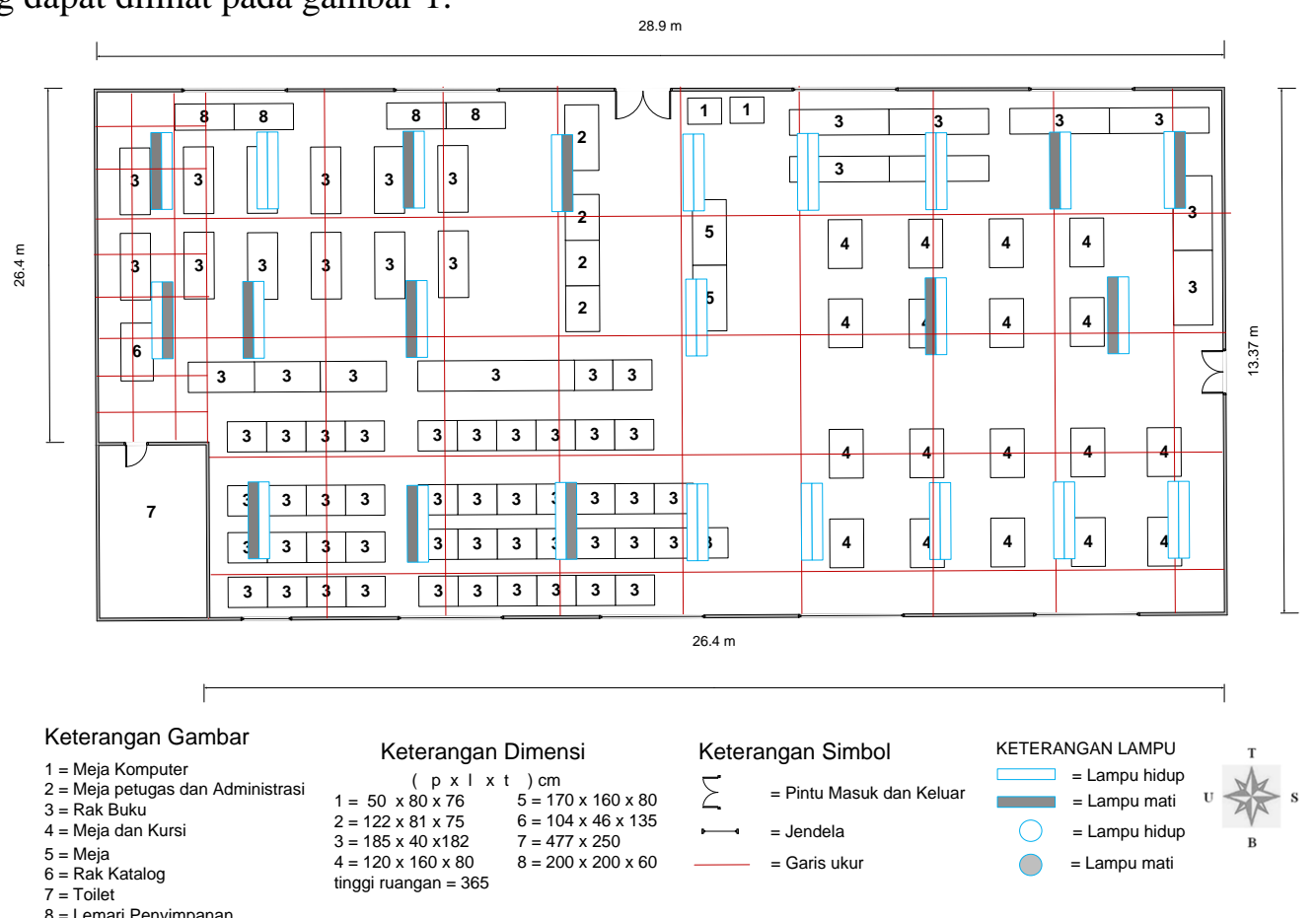

Gambar 1. Data kondisi ruang skripsi 
Ruang skripsi pada perpustakaan pusat UNS menggunakan dua jenis lampu yaitu lampu TL 36 watt dan lampu tornado 20 watt.Ruang skripsi terbagi menjadi dua bagian karena bentuk ruangan yang tidak simetris sehingga dibutuhkan pembagian ruangan. Menurut SNI 16-70622004 penentuan jarak antara titik ukur pada bagian Iadalah $3 \mathrm{~m} 2$ karena luas ruangan besarnya antara $10 \mathrm{~m} 2$ dan $100 \mathrm{~m} 2$ dan jarak antara titik ukur pada bagian II adalah $1 \mathrm{~m} 2$ karena luas ruangan besarnya kurang dari $10 \mathrm{~m} 2$. Setelah diketahui jumlah titik ukurnya, maka dilakukan pengukuran intensitas cahaya dengan menggunakan luxmeter yang telah dikalibrasi. Setalah itu dilakukan penentuan titik $(0,0)$ pada pojok ruangan untuk memudahkan dalam menentukan koordinat tiap titik ukur. Sumbu x dan sumbu y mewakili panjang dan lebar ruangan sedangkan sumbu z mewakili nilai intensitas cahaya. Koordinat tiap titik ukur dapat dilihat pada tabel 1.

Tabel 1. Data koordinat tiap titik ukur

\begin{tabular}{|c|c|c|c|}
\hline \multicolumn{4}{|c|}{ Waktu pengukuran 08.00-10.00 } \\
\hline Titik ukur & $\mathbf{x}$ & $\mathbf{y}$ & $\mathbf{z}$ \\
\hline $\mathrm{A}$ & 1 & 12,37 & 5,0 \\
\hline B & 2 & 12,37 & 20,0 \\
\hline $\mathrm{C}$ & 1 & 11,37 & 4,0 \\
\hline $\mathrm{D}$ & 2 & 11,37 & 23,7 \\
\hline $\mathrm{E}$ & 1 & 10,37 & 4,0 \\
\hline $\mathrm{F}$ & 2 & 10,37 & 18,3 \\
\hline $\mathrm{G}$ & 1 & 9,37 & 5,0 \\
\hline $\mathrm{H}$ & 2 & 9,37 & 18,7 \\
\hline I & 1 & 8,37 & 6,0 \\
\hline $\mathbf{J}$ & 2 & 8,37 & 17,7 \\
\hline $\mathrm{K}$ & 1 & 7,37 & 4,3 \\
\hline $\mathrm{L}$ & 2 & 7,37 & 27,0 \\
\hline M & 1 & 6,37 & 8,0 \\
\hline $\mathrm{N}$ & 2 & 6,37 & 34,7 \\
\hline $\mathrm{O}$ & 1 & 5,37 & 20,3 \\
\hline $\mathrm{P}$ & 2 & 5,37 & 22,0 \\
\hline Q & 5,5 & 10,37 & 42,7 \\
\hline $\mathrm{R}$ & 8,5 & 10,37 & 74,0 \\
\hline$S$ & 11,5 & 10,37 & 94,7 \\
\hline $\mathrm{T}$ & 14,5 & 10,37 & 83,0 \\
\hline $\mathrm{U}$ & 17,5 & 10,37 & 90,0 \\
\hline $\mathrm{V}$ & 20,5 & 10,37 & 75,0 \\
\hline $\mathrm{W}$ & 23,5 & 10,37 & 73,0 \\
\hline$X$ & 26,5 & 10,37 & 71,0 \\
\hline $\mathrm{Y}$ & 5,5 & 7,37 & 45,0 \\
\hline $\mathrm{Z}$ & 8,5 & 7,37 & 64,0 \\
\hline $\mathrm{AA}$ & 11,5 & 7,37 & 67,0 \\
\hline $\mathrm{AB}$ & 14,5 & 7,37 & 82,0 \\
\hline $\mathrm{AC}$ & 17,5 & 7,37 & 85,0 \\
\hline $\mathrm{AD}$ & 20,5 & 7,37 & 93,7 \\
\hline $\mathrm{AE}$ & 23,5 & 7,37 & 87,0 \\
\hline $\mathrm{AF}$ & 26,5 & 7,37 & 84,0 \\
\hline $\mathrm{AG}$ & 5,5 & 4,37 & 58,0 \\
\hline $\mathrm{AH}$ & 8,5 & 4,37 & 55,0 \\
\hline AI & 11,5 & 4,37 & 47,7 \\
\hline AJ & 14,5 & 4,37 & 74,0 \\
\hline $\mathrm{AK}$ & 17,5 & 4,37 & 89,0 \\
\hline $\mathrm{AL}$ & 20,5 & 4,37 & 61,0 \\
\hline $\mathrm{AM}$ & 23,5 & 4,37 & 61,3 \\
\hline AN & 26,5 & 4,37 & 54,0 \\
\hline $\mathrm{AO}$ & 5,5 & 1,37 & 44,3 \\
\hline AP & 8,5 & 1,37 & 32,0 \\
\hline $\mathrm{AQ}$ & 11,5 & 1,37 & 38,0 \\
\hline AR & 14,5 & 1,37 & 64,3 \\
\hline AS & 17,5 & 1,37 & 63,0 \\
\hline $\mathrm{AT}$ & 20,5 & 1,37 & 68,0 \\
\hline $\mathrm{AU}$ & 23,5 & 1,37 & 67,0 \\
\hline AV & 26,5 & 1,37 & 65,0 \\
\hline
\end{tabular}

\begin{tabular}{|c|c|c|c|}
\hline \multicolumn{4}{|c|}{ Waktu pengukuran 12.00-14.00 } \\
\hline Titik ukur & $\mathbf{x}$ & $\mathbf{y}$ & $\mathbf{z}$ \\
\hline $\mathrm{A}$ & 1 & 12,37 & 4,0 \\
\hline B & 2 & 12,37 & 21,3 \\
\hline $\mathrm{C}$ & 1 & 11,37 & 5,0 \\
\hline $\mathrm{D}$ & 2 & 11,37 & 22,7 \\
\hline$E$ & 1 & 10,37 & 5,3 \\
\hline $\mathrm{F}$ & 2 & 10,37 & 17,3 \\
\hline $\mathrm{G}$ & 1 & 9,37 & 4,3 \\
\hline $\mathrm{H}$ & 2 & 9,37 & 18,3 \\
\hline $\mathrm{I}$ & 1 & 8,37 & 5,3 \\
\hline $\mathrm{J}$ & 2 & 8,37 & 21,7 \\
\hline $\mathrm{K}$ & 1 & 7,37 & 5,0 \\
\hline $\mathrm{L}$ & 2 & 7,37 & 25,0 \\
\hline M & 1 & 6,37 & 8,3 \\
\hline $\mathrm{N}$ & 2 & 6,37 & 36,3 \\
\hline $\mathrm{O}$ & 1 & 5,37 & 22,0 \\
\hline $\mathrm{P}$ & 2 & 5,37 & 22,0 \\
\hline $\mathrm{Q}$ & 5,5 & 10,37 & 42,3 \\
\hline $\mathrm{R}$ & 8,5 & 10,37 & 84,7 \\
\hline$S$ & 11,5 & 10,37 & 95,0 \\
\hline $\mathrm{T}$ & 14,5 & 10,37 & 152,3 \\
\hline $\mathrm{U}$ & 17,5 & 10,37 & 158,0 \\
\hline $\mathrm{V}$ & 20,5 & 10,37 & 154,0 \\
\hline $\mathrm{W}$ & 23,5 & 10,37 & 133,7 \\
\hline$X$ & 26,5 & 10,37 & 124,0 \\
\hline $\mathrm{Y}$ & 5,5 & 7,37 & 45,3 \\
\hline $\mathrm{Z}$ & 8,5 & 7,37 & 68,0 \\
\hline AA & 11,5 & 7,37 & 69,0 \\
\hline $\mathrm{AB}$ & 14,5 & 7,37 & 148,0 \\
\hline $\mathrm{AC}$ & 17,5 & 7,37 & 150,0 \\
\hline $\mathrm{AD}$ & 20,5 & 7,37 & 131,7 \\
\hline $\mathrm{AE}$ & 23,5 & 7,37 & 121,0 \\
\hline $\mathrm{AF}$ & 26,5 & 7,37 & 112,0 \\
\hline $\mathrm{AG}$ & 5,5 & 4,37 & 45,0 \\
\hline $\mathrm{AH}$ & 8,5 & 4,37 & 54,0 \\
\hline $\mathrm{AI}$ & 11,5 & 4,37 & 49,0 \\
\hline AJ & 14,5 & 4,37 & 78,0 \\
\hline AK & 17,5 & 4,37 & 90,0 \\
\hline AL & 20,5 & 4,37 & 81,0 \\
\hline $\mathrm{AM}$ & 23,5 & 4,37 & 86,0 \\
\hline AN & 26,5 & 4,37 & 95,0 \\
\hline $\mathrm{AO}$ & 5,5 & 1,37 & 52,0 \\
\hline AP & 8,5 & 1,37 & 46,7 \\
\hline $\mathrm{AQ}$ & 11,5 & 1,37 & 48,0 \\
\hline AR & 14,5 & 1,37 & 152,0 \\
\hline AS & 17,5 & 1,37 & 155,0 \\
\hline $\mathrm{AT}$ & 20,5 & 1,37 & 122,0 \\
\hline $\mathrm{AU}$ & 23,5 & 1,37 & 123,0 \\
\hline AV & 26,5 & 1,37 & 118,3 \\
\hline
\end{tabular}

\begin{tabular}{|c|c|c|c|}
\hline \multicolumn{4}{|c|}{ Waktu pengukuran 16.00-18.00 } \\
\hline Titik ukur & $\mathbf{x}$ & $\mathbf{y}$ & $\mathbf{z}$ \\
\hline $\mathrm{A}$ & 1 & 12,37 & 4,0 \\
\hline $\mathrm{B}$ & 2 & 12,37 & 20,0 \\
\hline C & 1 & 11,37 & 5,0 \\
\hline $\mathrm{D}$ & 2 & 11,37 & 22,0 \\
\hline E & 1 & 10,37 & 4,0 \\
\hline $\mathrm{F}$ & 2 & 10,37 & 18,0 \\
\hline $\mathrm{G}$ & 1 & 9,37 & 6,0 \\
\hline $\mathrm{H}$ & 2 & 9,37 & 16,7 \\
\hline I & 1 & 8,37 & 4,0 \\
\hline $\mathbf{J}$ & 2 & 8,37 & 16,3 \\
\hline $\mathrm{K}$ & 1 & 7,37 & 4,0 \\
\hline $\mathrm{L}$ & 2 & 7,37 & 21,7 \\
\hline M & 1 & 6,37 & 8,0 \\
\hline $\mathrm{N}$ & 2 & 6,37 & 36,0 \\
\hline $\mathrm{O}$ & 1 & 5,37 & 21,7 \\
\hline $\mathrm{P}$ & 2 & 5,37 & 22,0 \\
\hline Q & 5,5 & 10,37 & 41,3 \\
\hline $\mathrm{R}$ & 8,5 & 10,37 & 73,3 \\
\hline $\mathrm{S}$ & 11,5 & 10,37 & 95,0 \\
\hline $\mathrm{T}$ & 14,5 & 10,37 & 85,0 \\
\hline $\mathrm{U}$ & 17,5 & 10,37 & 88,0 \\
\hline $\mathrm{V}$ & 20,5 & 10,37 & 82,0 \\
\hline W & 23,5 & 10,37 & 82,3 \\
\hline $\mathrm{X}$ & 26,5 & 10,37 & 80,0 \\
\hline $\mathrm{Y}$ & 5,5 & 7,37 & 43,0 \\
\hline Z & 8,5 & 7,37 & 68,0 \\
\hline AA & 11,5 & 7,37 & 64,0 \\
\hline $\mathrm{AB}$ & 14,5 & 7,37 & 94,0 \\
\hline $\mathrm{AC}$ & 17,5 & 7,37 & 82,0 \\
\hline $\mathrm{AD}$ & 20,5 & 7,37 & 83,3 \\
\hline $\mathrm{AE}$ & 23,5 & 7,37 & 86,0 \\
\hline $\mathrm{AF}$ & 26,5 & 7,37 & 85,0 \\
\hline AG & 5,5 & 4,37 & 57,0 \\
\hline $\mathrm{AH}$ & 8,5 & 4,37 & 55,3 \\
\hline AI & 11,5 & 4,37 & 42,0 \\
\hline $\mathrm{AJ}$ & 14,5 & 4,37 & 73,0 \\
\hline $\mathrm{AK}$ & 17,5 & 4,37 & 90,0 \\
\hline AL & 20,5 & 4,37 & 80,0 \\
\hline AM & 23,5 & 4,37 & 83,0 \\
\hline AN & 26,5 & 4,37 & 57,0 \\
\hline $\mathrm{AO}$ & 5,5 & 1,37 & 53,0 \\
\hline AP & 8,5 & 1,37 & 44,3 \\
\hline $\mathrm{AQ}$ & 11,5 & 1,37 & 46,0 \\
\hline $\mathrm{AR}$ & 14,5 & 1,37 & 121,0 \\
\hline AS & 17,5 & 1,37 & 114,3 \\
\hline AT & 20,5 & 1,37 & 105,3 \\
\hline $\mathrm{AU}$ & 23,5 & 1,37 & 111,3 \\
\hline $\mathrm{AV}$ & 26,5 & 1,37 & 108,7 \\
\hline
\end{tabular}


Setelah menentukan koordinat titik ukur. Hal selanjutnya yang dilakukan adalah melakukan pengolahan data dengan menggunakan surfer V.10 yang hasilnya dapat dilihat pada gambar 2.
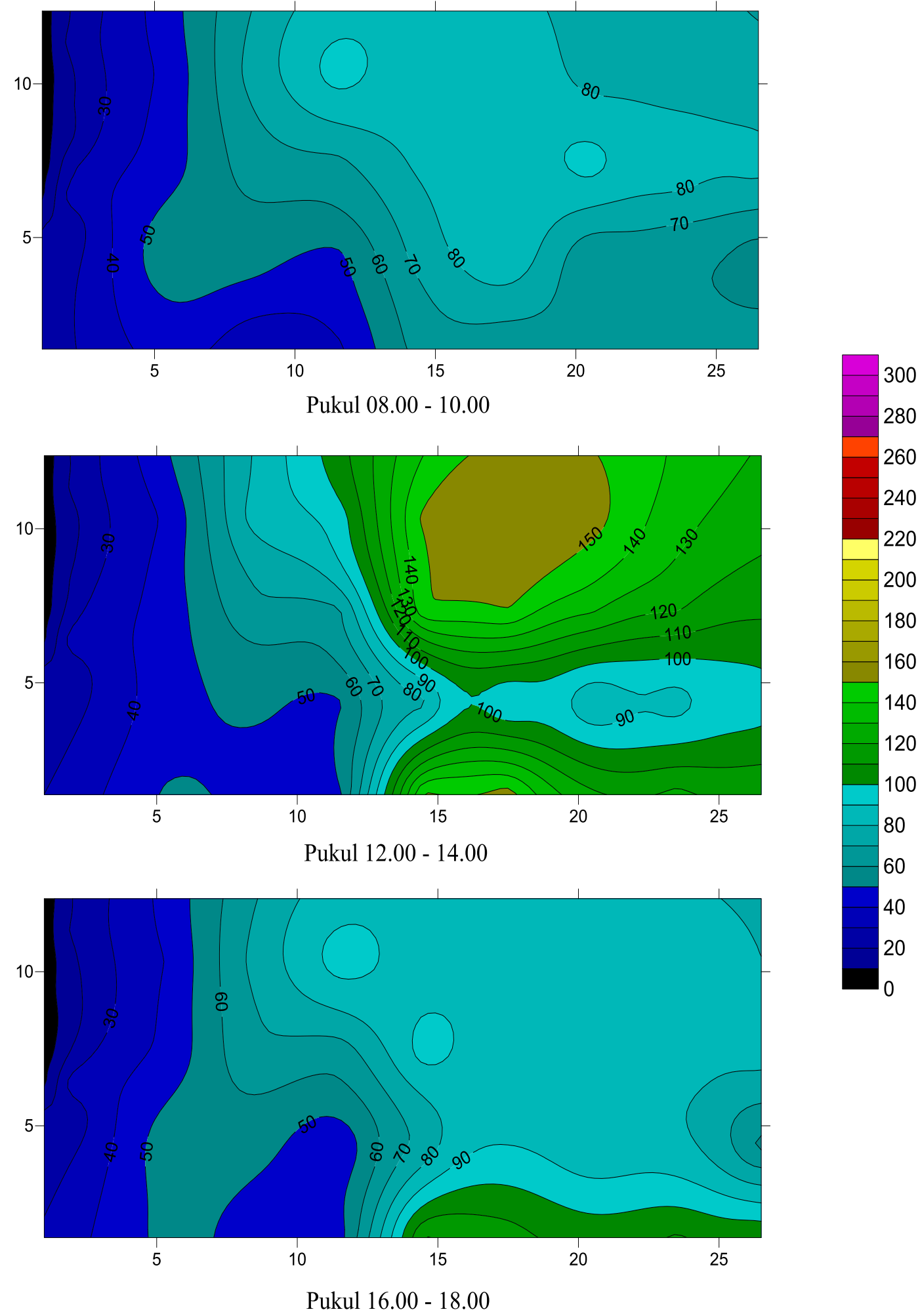

Gambar 2. Hasil pengolahan surfer V.10 
Gambar 2 menunjukan bahwa tingkat pencahayaan yang tinggi hanya terkumpul di tiap pinggir ruangan yang terkena sinar matahari yang masuk melalui jendela. Hal itu terlihat pada pengukuran pukul pukul 12.00-14.00 dan pukul 16.00-18.00. Dari gambar diatas juga bisa dilihat bahwa intensitas cahaya matahari yang masuk Pada pukul 12.00-14.00 paling tinggi dibandingkan dengan yang lain intensitas cahaya. Intensitas cahaya matahari pada pukul 16.0018.00 lebih besar daripada pukul 08.00-10.00 disebabkan posisi ruang skripsi yang terletak pada sebelah barat bangunan serta pada sore hari poisi matahari ada di sebelah barat Rendahnya nilai intensitas cahaya pada ruang lima bagian II yang terletak di bagian atas disebakan oleh letaknya yang jauh dari jendela dan hanya mengandalkan 2 buah lampu TL sebagai penerangan. serta banyaknya rak buku pada bagian tersebut sehingga pada saat pengukuran terhalang oleh bayangan yang ditimbulkan rak buku. Distribusi cahaya pada tiga waktu pengukuran masih jauh dibawah standar yang telah ditetapkan oleh SNI 03-6575-2001 sebesar 300 lux.jika pengguna perpustakaan dibiarkan beraktivitas dengan keadaan pencahayaan yang tidak layak, maka cepat atau lambat mereka akan mengalami keluhan kelelahan mata yang akan mengakibatkan gangguan kesehatan. Sehingga perlu dilakukan usulan perbaikan terhadap sistem pencahayaan saat ini.

Proses usulan perbaikan pencahayaan pada ruang skripsi hanya berfokus pada pencahayaan buatan sehingga ruang skripsi dikondisikan menggunakan screening device/tirai yang menutup jendela sehingga menghalangi masuknya pencahayaan alami (sinar matahari) dari luar. Penutupan semua ruang disebabkan oleh besarnya intensitas matahari yang masuk dalam ruangan cenderung tidak konsisten.Selain itu besarnya intensitas cahaya matahari tergantung dari dua faktor yaitu letak ruangan dan waktu. Menurut Lasa (2005) cahaya matahari atara pukul 09.00 sampai pukul 14.00 sebaiknya tidak masuk ruang perpustakaan, sebab cahaya pada jam-jam tersebut mengandung radiasi panas yang merugikan manusia dan memperpendek daya bahan pakai pustaka, baik yang berupa kertas maupun non kertas. Bahan informasi yang terdiri dari kertas apabila terkena sinar matahari akan segera lapuk, tulisannya memudar, dan warna kertasnya akan menjadi kuning kecoklatan.

Pemilihan warna plafon dan warna lantai untuk perpustakaan UNS adalah wana putih.Hal ini disebabkan nilai tertinggi untuk faktor refleksi dinding adalah wana putih.Semakin besar faktor refleksinya maka jumlah lumen yang dibutuhkan semakin kecil pula.Sedangkan untuk warna dinding dipilih warna yang berbeda yaitu warna biru muda. Hal tersebut dikarenakan agar warna dalam ruangan tidak monoton selain itu warna biru muda akan menimbulkan kesan damai, tenang, lembut, dan santai bagi efek psikologis pengguna (prafulla,1987).

Jenis armatur yang digunakan adalah armatur tipe TKI yang di pasang menempel pada langit-langit.Untuk tiap armatur berisi 2 buah lampu (n).Sistem pencahayaan yang digunakan adalah sistem pencahayaan merata. Jumlah armatur yang didapat dari perhitungan akan disebar merata keseluruh ruangan. Sistem pencahayaan ini dipilih agar intensitas cahaya yang direkomendasikan oleh SNI 03-6575-2001 sebesar 300 lux dapat menyebar merata keseluruh ruangan.Dalam melakukan perancangan pencahayaan buatan harus memperhatikan daya listrik per meter persegi. Daya listrik per meter persegi tidak boleh melebihi daya maksimum yang dizinkan menurut SNI $6197: 2011$, yaitu sebesar $11 \mathrm{w} / \mathrm{m}^{2}$.

Proses usulan perbaikan ruang skrispsi dilakukan dengan metode lumen dan pada dua kondisi yang berbeda, yaitu kondisi pertama menggunakan lampu TL 36 watt sedangkan kondisi kedua menggunakan lampu sehen LED 22 watt tipe ZGSM-T8-1500-300P. Untuk hasil perhitungan tiap langkahnya dpat dilihat pada tabel 2 . 
Tabel 2. Hasil Perhitungan dengan metode lumen

\begin{tabular}{|l|c|c|}
\hline \multicolumn{1}{|c|}{ Perhitungan } & Lampu TL 36 watt & Lampu LED 22 watt \\
\hline Tingkat pencahayaan minimum (E) & 300 lux & 300 lux \\
Koefien penggunaan (Kp) bagian I & 0,613 & 0,613 \\
Koefien penggunaan (Kp) bagian II & 0,332 & 0,332 \\
Koefisien depresiasi (Kd) & 1 & 1 \\
Jumlah flux luminus (F total) bagian I & 172622,013 lumen & 172622,013 lumen \\
Jumlah flux luminus (F total) bagian II & 19436,446 lumen & 19436,446 lumen \\
Jumlah armatur (N) bagian I & 68 & 96 \\
Jumlah armatur (N) bagian II & 8 & 12 \\
Biaya instalasi armatur pertitik & $\mathrm{Rp} 40,000.00$ & $\mathrm{Rp} 40,000.00$ \\
Biaya instalasi armatur & $\mathrm{Rp} 3.040 .000,00$ & $\mathrm{Rp} 4.320 .000,00$ \\
Daya terpasang & 7,306 & 6,345 \\
Biaya kwh/tahun & $\mathrm{Rp} 508,348.80$ & $\mathrm{Rp} 441,460.80$ \\
\hline
\end{tabular}

Dari tabel diatas dapat dilihat bahwa biaya listrik/bulan yang dikeluarkan oleh LED 22 watt lebih murah dari TL 36 watt walaupun jumlah lampu yang diperlukan lebih sedikit. Hal tersebut disebabkan lumen/watt LED 22 watt lebih besar daripada lumen/watt yang dimiliki oleh lampu TL 36 watt. Oleh karena itu dalam usulan perbaikan yang dilakukan akan menggunakan lampu LED karena hemat energi. Selain itu umur lampu LED lebih panjang daripada lampu TL yaitu sekitar 50.000 jam atau 5-6 kali umur lampul TL.

\section{Simpulan dan Saran}

Dari seluruh tahap-tahap penelitian yang telah dilaksanakan, maka dapat ditarik kesimpulan yaitu kondisi sistem pencahayaan existing pada ruang perpustakaan pusat UNS sangat kurang memadai dan tidak layak untuk menunjang aktivitas visual yang memerlukan tingkat pencahayaan yang tinggi seperti membaca dan menulis. Diperlukan sebuah perbaikan untuk mencapai tingkat pencahayaan ideal yang sesuai standar, maka usulan perbaikan dilakukan sesuai dengan tingkat pencahayaan minimal yang direkomendasikan oleh SNI 036575-2001 yaitu memberikan tirai penutup pada jendela, mengganti warna dinding dengan warna biru muda, dan mengganti lampu yang digunakan pada saat ini dengan lampu LED yang memiliki nilai lumen/watt yang tinggi, sehingga biaya listrik yang dikeluarkan lebih murah.

Saran yang dapat diberikan untuk perpustakaan pusat UNS dan langkah pengembangan untuk penelitian selanjutnya adalah melakukan proses analisa lebih lanjut tentang hubungan kelelahan mata yang terjadi dengan tingkat pencahayaan pada perpustakaan pusat UNS dan melakukan validasi atas usulan perbaikan yang telah dilakukan.

\section{Daftar Pustaka}

Hendra,Sekar T.A.N.P., dan Amah M.V.D.(2010).Analisis Tingkat Pencahayaan pada Perpustakaan di Lingkungan Universitas Indonesia, Penelitian Hibah RU UI Utama, Universitas Indonesia, Depok.

Lasa, HS. (2005). Manajemen Perpustakaan.Yogyakarta: Gama Media.

Ming-chin, H., Cheming, C., Po-Cheng, C., Kuei-Feng., C dan Chia-Yu L. (2008). Optimal sun-shading design for enhanced daylight illumination of subtropical classrooms, Energy and Buildings, Elvesier BV, Vol 40, 1844-1855, Taiwan.

Natassia, Napitupulu. (2009). Gambaran Penerapan Ergonomi Ruang Kerja. FKM Universitas Indonesia, Depok

Nurmianto, Eko. (2004.) Ergonomi Konsep Dasar dan Aplikasinya Edisi 2. Surabaya : Gunawidya

Notoatmodjo.(2003). Pengantar pendidikan Kesehatan dan Ilmu Perilaku. Rineka Cipta. Jakarta.

Padmanaba. (2006).Pengaruh Penerangan dalam Ruang Terhadap Produktivitas Kerja Mahasiswa Desain Interior; Majalah Dimensi Interior; Edisi Desember 2006. 
Prafulla C. Sorcar. (1987). Architechural Lighting for Commercial Interiors, United states of America, john wiley and sons, inc.

Standar Nasional Indonesia.(2001).Tata Cara Perancangan Sistem Pencahayaan Buatan Pada Bangunan Gedung.SNI 03-6575-2001. Diunduh pada 10 September 2013

Standar Nasional Indonesia.(2004).Pengukuran Intensitas Penerangan di Tempat Kerja.SNI 167062-2004. Diunduh pada 10 september 2013

Sumardjati, dkk. (2008). Teknik Pemanfaatan Tenaga Listrik Jilid 1 untuk SMK. Direktorat Pembinaan Sekolah Menengah Kejuruan, Direktorat Jenderal Manajemen Pendidikan Dasar dan Menengah, Departemen Pendidikan Nasional. Jakarta.

Yuven, Yuni.(2010). Perpustakaan Perguruan Tinggi Pedoman Pengelolaan dan Standarisasi www. http:/yuni_yuven.blog.undip.ac.id. Diunduh pada 02 februari 2013. 